\title{
Respiratory disease associated with solid biomass fuel exposure in rural women and children: systematic review and meta-analysis
}

\author{
June Y T Po, J Mark FitzGerald, Chris Carlsten
}

Department of Medicine, The University of British Columbia, Vancouver, British Columbia, Canada

\section{Correspondence to}

Chris Carlsten, Department of Medicine, The University of British Columbia, Vancouver General Hospital, 7th Floor, 2775 Laurel St, Vancouver, BC V5Z 1M9, Canada; chris.carlsten@vch.ca

Received 27 July 2010 Accepted 9 December 2010 Published Online First 19 January 2011

\begin{abstract}
Background Numerous studies with varying associations between domestic use of solid biomass fuels (wood, dung, crop residue, charcoal) and respiratory diseases have been reported.

Objective To present the current data systematically associating use of biomass fuels with respiratory outcomes in rural women and children.

Methods Systematic searches were conducted in 13 electronic databases. Data were abstracted from original articles that satisfied selection criteria for meta-analyses. Publication bias and heterogeneity of samples were tested. Studies with common diagnoses were analysed using random-effect models.

Results A total of 2717 studies were identified. Fifty-one studies were selected for data extraction and 25 studies were suitable for meta-analysis. The overall pooled ORs indicate significant associations with acute respiratory infection in children (OR 3.53, 95\% $\mathrm{Cl} 1.94$ to 6.43), chronic bronchitis in women (OR 2.52,95\% Cl 1.88 to 3.38 ) and chronic obstructive pulmonary disease in women (OR 2.40, 95\% Cl 1.47 to 3.93). In contrast, no significant association with asthma in children or women was noted.

Conclusion Biomass fuel exposure is associated with diverse respiratory diseases in rural populations. Concerted efforts in improving stove design and lowering exposure to smoke emission may reduce respiratory disease associated with biomass fuel exposure.
\end{abstract}

\section{INTRODUCTION}

About 2.4 billion people live in households where the source of energy for cooking and heating is solid biomass fuels. Another 0.6 billion people use coal. $^{1} 2$ Solid biomass fuels are typically wood, charcoal, dried animal dung and agricultural residues such as straw and sticks, which have low combustion efficiency. Incomplete combustion leads to discharge of smoke formed by fine particulate matter, which fills the kitchen or living area. Other fuel types that are higher on the 'energy ladder' are kerosene, liquefied petroleum gas (LPG) and electricity. ${ }^{3}$ Often households cannot afford these alternative fuels; instead, they opt to collect wood, agricultural residue and animal dung as household fuels. ${ }^{4}$ In biomass-burning households, $\mathrm{PM}_{10}$ (inhalable material $<10 \mu \mathrm{m}$ in aerodynamic diameter) or $\mathrm{PM}_{2.5}$ often exceed guideline levels of mean $24 \mathrm{~h}$ concentration and severely more so during cooking. ${ }^{5-7}$

Exposure to solid fuel may have contributed to 1.6 million cases of premature mortality and $>38.5$ million disability-adjusted life-years (DALYs) in $2000,{ }^{2}$ leading to $\sim 4 \%$ of the global health burden. ${ }^{5}$ Population growth and the rising price of alternative fuel such as kerosene and LPG increase the use of biomass fuels in developing countries. The daily smoke exposure household members face poses a severe yet largely preventable health risk. About 2 million children under 5 die from pneumonia. Exposure to indoor air pollution doubles the risk of pneumonia and other acute lower respiratory infections (ALRIs), contributing to $>800000$ deaths in children under $5 .^{8}$ In adults, chronic obstructive pulmonary disease (COPD) and chronic bronchitis (CB) are becoming major causes of chronic morbidity and mortality in developing countries. In 2001, it was the fifth and sixth highest cause of death in females and males, respectively, from lowand middle-income countries. ${ }^{9}$ Likewise, exposure to biomass smoke increases the risk of respiratory disease such as COPD, asthma and tuberculosis in adults. ${ }^{1}$

Among adults in low- and middle-income countries, women and children are disproportionately impacted by the exposure to biomass smoke. As in most cultures, women take on the role of cooking in the family. Some begin at a young age by helping their mothers prepare food, spending between 3 and $7 \mathrm{~h}$ per day near the stove for many years. Infants are sometimes carried on their mother's back for care and warmth while the mother cooks, exposing them to levels of biomass smoke similar to their mother. ${ }^{10}$

The associations between indoor air pollution exposure and specific respiratory diseases in certain age groups have been reported and reviewed descriptively ${ }^{1} \quad 4 \quad 11 \quad 12$ and quantitatively. ${ }^{13-15}$ Previous systematic reviews and meta-analyses concluded that indoor air pollution exposure from unprocessed solid fuel use not only increases the risk of pneumonia in young children by a factor of $1.8,{ }^{13}$ but also more than doubles the risk of COPD and $\mathrm{CB}$ in adults. ${ }^{14}{ }^{15}$ However, there were also individual studies reporting conflicting results between association of biomass fuel exposure and asthma. ${ }^{16-19}$ Randomised stove intervention trials in Guatemala are providing results on chronic lung symptoms and lung functions with exposure assessment, but estimates on common respiratory diagnoses such as COPD and CB are yet to come. ${ }^{20}$ The present meta-analysis focuses specifically on the respiratory health impact of rural women and children with biomass fuel exposure. Men were not targeted in this study as previous literature has shown across several developing countries in several 
continents that males have much greater exposure to tobacco smoke than females, which would probably confound the association of their respiratory illnesses with biomass fuel exposure. $^{21-23}$ Unlike previous meta-analyses, this study explores a wider range of respiratory illnesses including acute respiratory infections (ARIs), asthma, COPD and CB across all age groups. This study strengthens collective evidence on the hazardous exposure of unprocessed biomass fuel used by over half the world's population. Along with other reviews, it aims to convey the direness of the biomass fuel exposure in vulnerable populations and inform policy decision-makers to consider measures that could reduce biomass fuel-associated exposures.

\section{METHODS}

\section{Selection of studies and review process}

We identified relevant publications by systematic searches in eight peer-reviewed literature databases (CINAHL, EMBASE, Family and Society Studies World Wide, LILACS, MEDLINE, Sociological Abstracts, TOXNET, Web of Science) and five grey literature databases (British Library, PaperFirst, ProceedingsFirst, ProQuest Dissertations and Theses, WHOLIS) up to February 2008. Broad inclusion criteria for articles were (1) exposure to biomass (wood, animal dung, crop residue, charcoal); (2) respiratory-related disease, symptoms and functioning; and (3) nonindustrialised or domestic settings for all age groups, gender, interventions and study designs. Search terms from the first criterion are: 'biomass', 'biofuel', 'biomass fuel', 'environmental exposure', 'indoor air pollution', 'particulate matter', 'carbon monoxide', 'woodsmoke' and 'smoke'. Search terms from the second criterion include respiratory tract disease terms, respiratory function tests and all the related terms under these broad categories. Search terms from the third criterion are: 'rural population', 'suburban population', 'poverty', 'poverty areas', 'developing countries' and 'non-industrial'. All terms under broad categories of geographical locations such as 'Africa', 'Americas', 'Asia' and 'Oceanic islands' were included. The three search results were combined with Boolean search function 'and'. A similar literature search process was repeated in the different databases.

The articles fulfilling all three criteria were included in the list of literature for further review (figure 1).

Duplications were removed from the total number of studies found from multiple database searches. The remaining articles were reviewed according to exclusion criteria based on title and abstract. Articles with exposure due to outdoor air pollution,

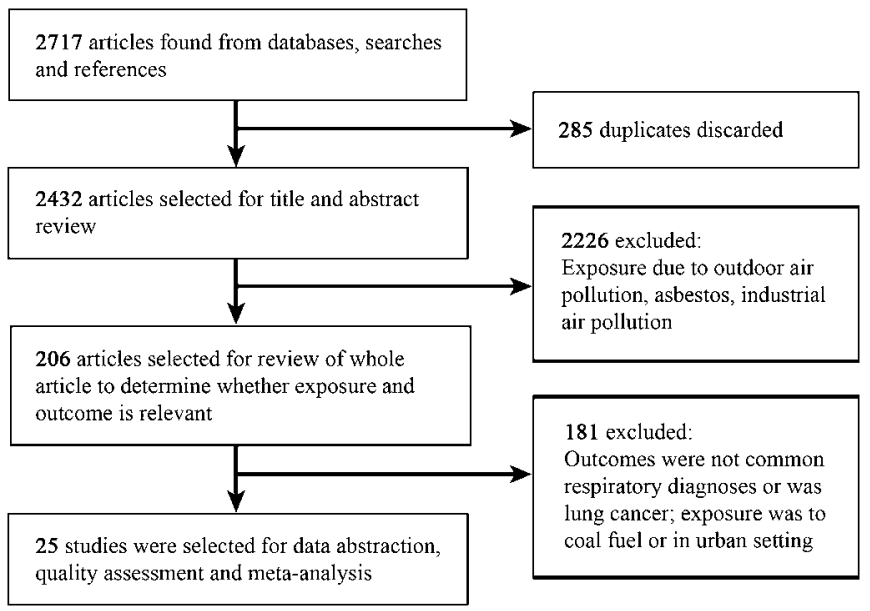

Figure 1 Study selection flow chart. asbestos and other industrial and occupational air pollution were excluded. The remaining articles were selected for review of their whole content. Articles were excluded where statistical association between exposure to biomass smoke and respiratory diseases found in women could not be isolated from that in men. Articles that were not original studies or did not provide calculable or reported ORs and 95\% CIs were also excluded from the meta-analysis. Studies with similar effect measures (eg, risk ratios) were included and used to approximate ORs.

Those articles that formally meet the inclusion criteria were appraised using a piloted data extraction form. Information on study design, population, biomass fuel source, respiratory disease, statistical techniques, confounding factors and results were extracted. Articles that did not report ORs but provided sufficient data for OR calculations were included.

\section{Statistical methods}

The statistical software Stata (Version 10, Stata Corporation) was used to generate forest plots and pooled ORs for groups of respiratory illness. We grouped studies with common diagnoses such as ARI and ALRI in spite of the fact that the precise definition of such diagnoses might have some variability between studies. The pooled ORs were generated from log ORs and standard errors abstracted from the articles. The criterion for random effect meta-analysis was determined by significant heterogeneity with an $\mathrm{I}^{2}$ statistic value $>50 \%$. Due to statistical heterogeneity between studies in design, geographic location, age groups, exposure to different fuel smoke and different confounding factors, random-effects models were used. Sources of heterogeneity were systematically examined by multivariable meta-regression. ${ }^{24}$ The regression models provided restricted maximum likelihood (REML) estimates of study design parameters and the residual between-trial variance. The Begg funnel plot $^{2526}$ and the Egger test ${ }^{25}$ were used to assess publication bias.

\section{RESULTS}

A total of 2717 studies from 1974 to the present were identified, and 51 studies were selected for data extraction. There were 25 original studies that met the inclusion criteria for meta-analysis. Nine were case-control studies ${ }^{17} 19^{27-33}$ and 16 were crosssectional studies. ${ }^{16} 18$ 34-47 Data from the 25 studies were sampled across 14 different countries starting from 1985 to the present. Sample sizes across the studies ranged from 50 women exposed to biomass fuels and 50 controls, ${ }^{34}$ to large samples of $>33000$ children $^{45}$ and 18000 women. ${ }^{42}$ Children from 1 month old to women $>60$ years old were sampled. The articles selected provided data for five subgroups: ARI in children, asthma in children, asthma in women, $\mathrm{CB}$ in women and COPD in women, summarised in table 1

Individual estimates from 25 studies and their overall pooled ORs grouped by respiratory illnesses are presented in the forest plot in figure 2. Eight of the 25 studies compared children exposed to biomass fuels and children exposed to kerosene, LPG, paraffin, gas, electricity or cleaner fuel in general. ${ }^{16} 2831323843-45$ The meta-analysis of the eight studies found that children were more than three times more likely to have ARIs when exposed to biomass fuel smoke than when exposed to cleaner fuel (OR 3.52, $95 \%$ CI 1.94 to 6.43). A random-effect model was used for the meta-analysis to adjust for heterogeneity among studies $\left(\mathrm{I}^{2}=91.3 \%, \mathrm{p}<0.001\right)$.

Six of the 25 studies measured $\mathrm{CB}$ in women as one of their outcomes. The studies compared women exposed to biomass fuels and women exposed to LPG or fuel oil, or with no exposure to biomass. ${ }^{273437394147}$ The meta-analysis of the six studies 


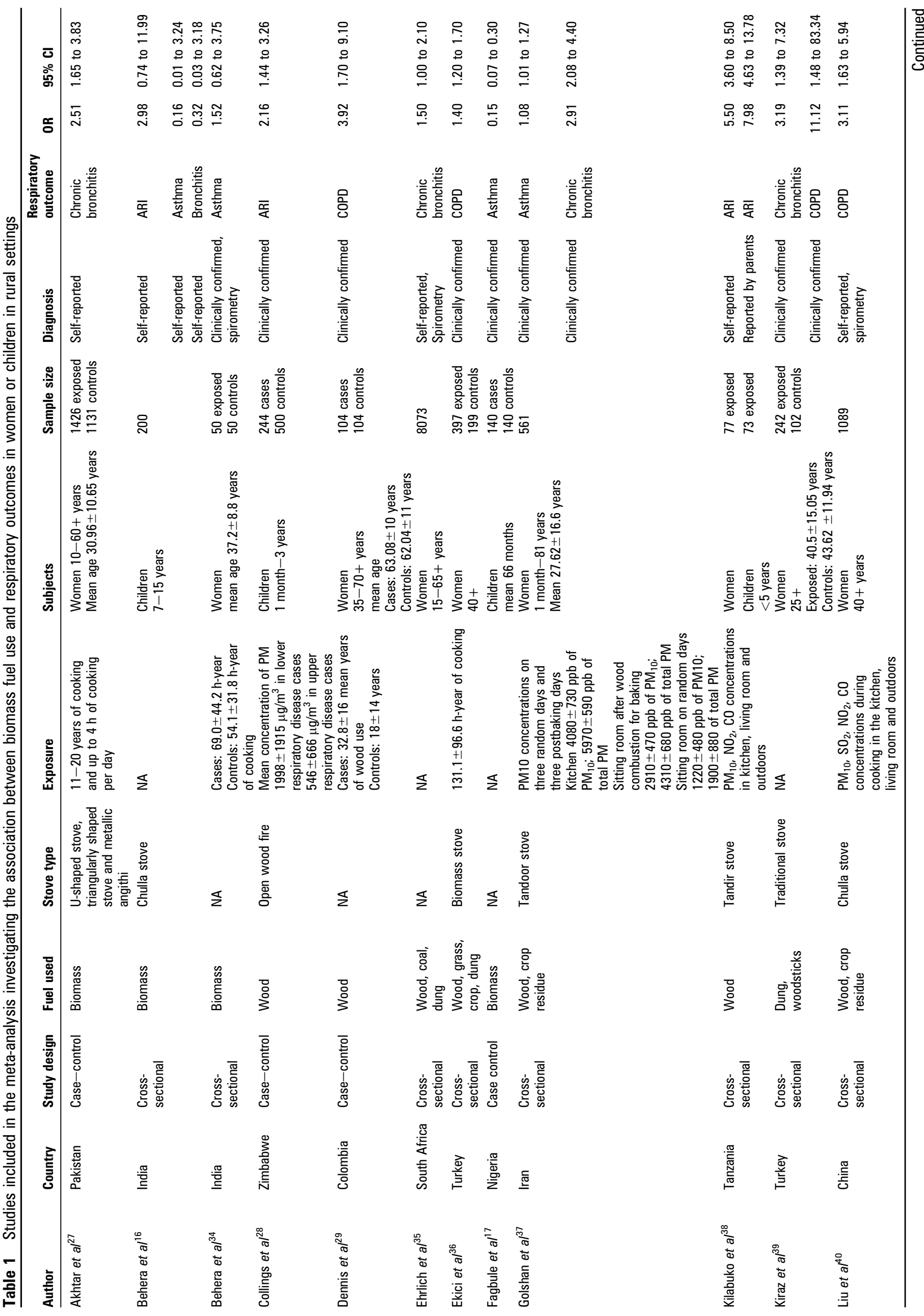




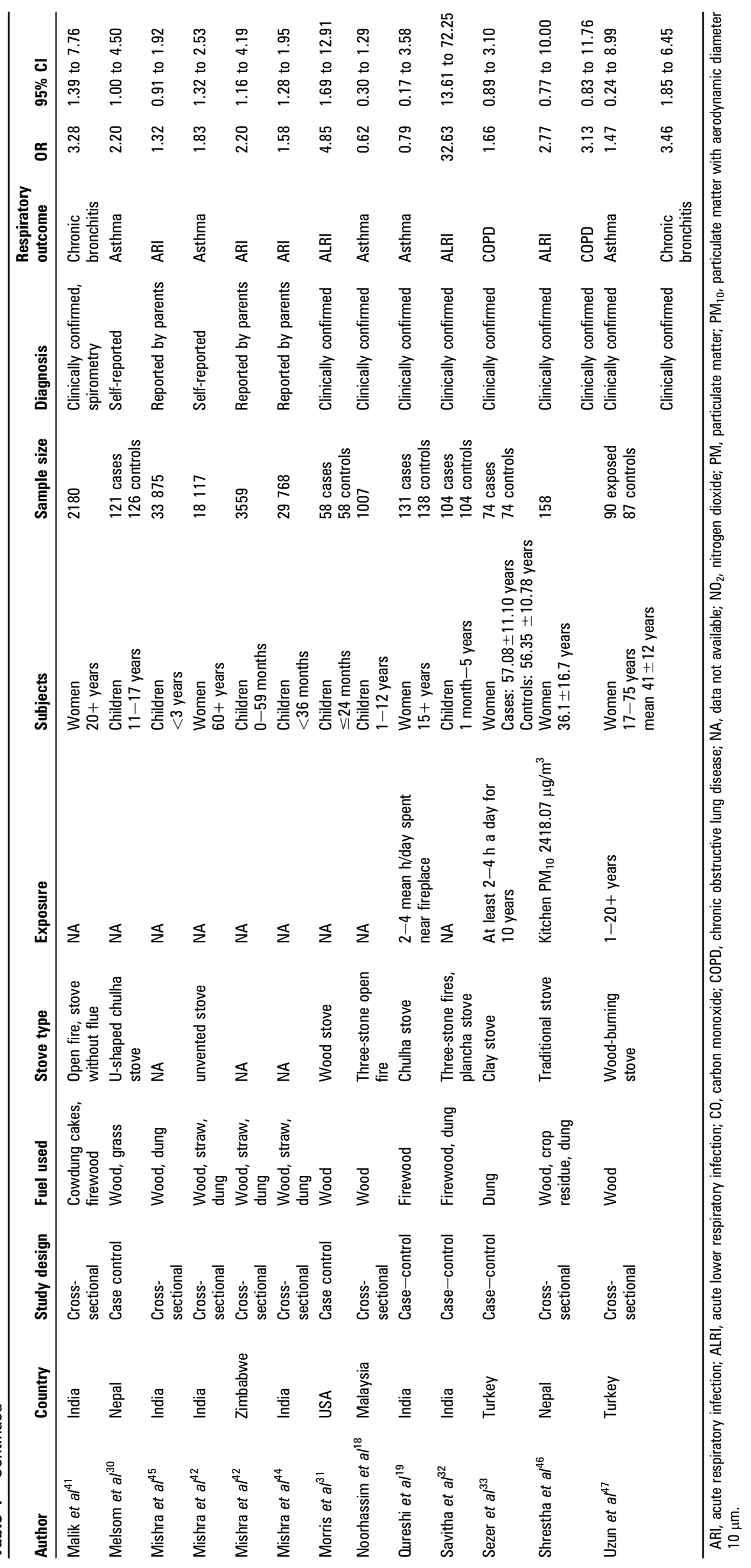


Figure 2 Forest plot of biomass fuel compared with other fuel type exposure and respiratory illnesses in children and women.

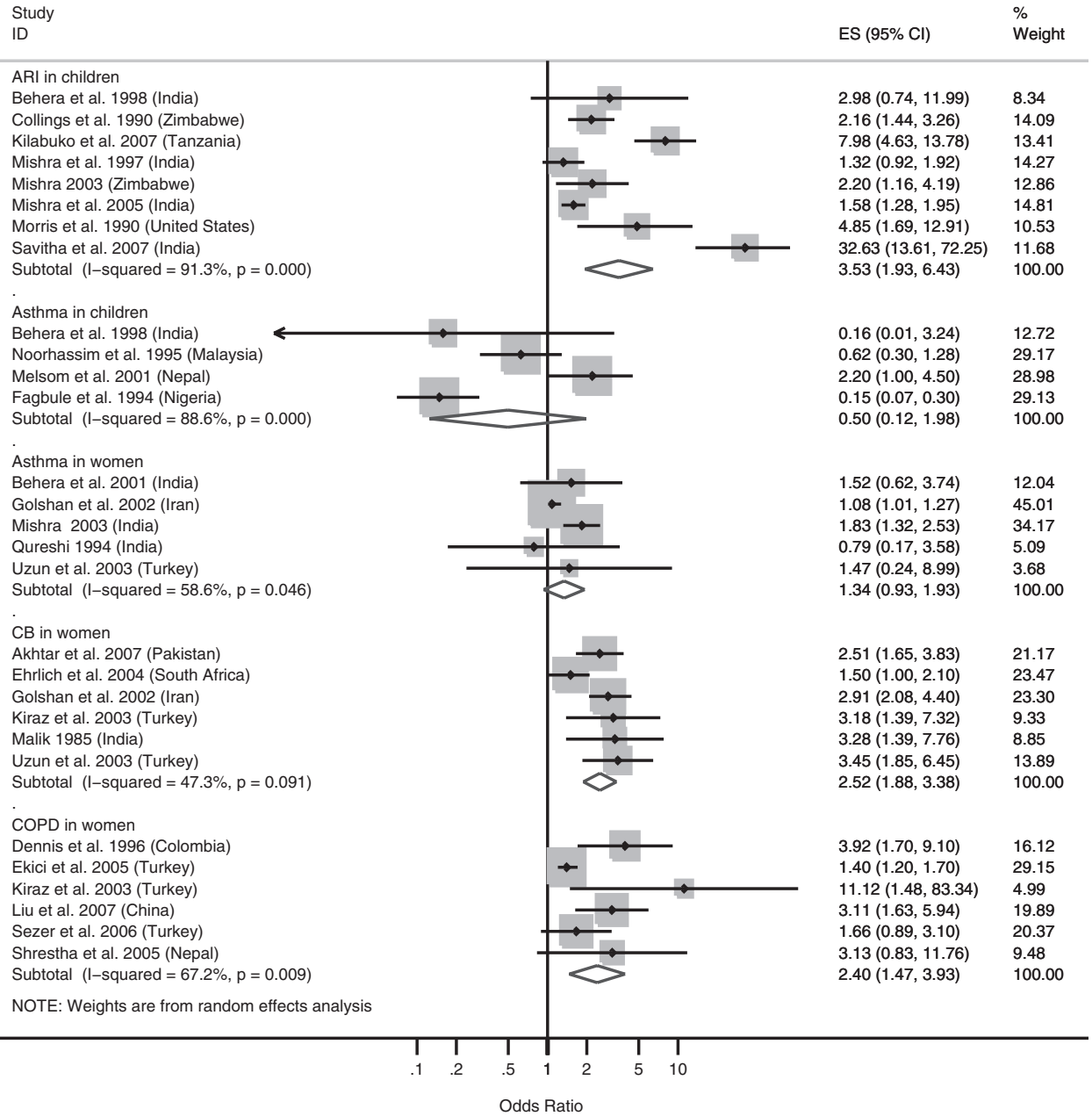

found that exposure to biomass fuel smoke was significantly associated with $\mathrm{CB}(\mathrm{OR}=2.52 ; 95 \% \mathrm{CI}=1.88$ to 3.38$)$. A random-effect model was used for the meta-analysis even though borderline heterogeneity among studies resulted in a non-significant $\mathrm{I}^{2}$ value $\left(\mathrm{I}^{2}=47.3 \% \mathrm{p}=0.091\right)$.

Another six studies measured COPD in women exposed to biomass fuels and women exposed to LPG, gasoline or oil. ${ }^{29} 33 \quad 36 \quad 3940 \quad 46$ Women exposed to biomass fuel smoke were 2.4 time more likely to develop COPD (OR 2.40, 95\% CI 1.47 to 3.93$)$. The random-effect model was used to adjust for heterogeneity among studies $\left(\mathrm{I}^{2}=67.2 \%, \mathrm{p}<0.001\right)$.

In contrast, the meta-analyses of studies on asthma in children or women did not find significant association with biomass fuel exposure. Meta-analysis of four studies on asthma in children exposed to biomass fuels were inconclusive, yielding a pooled OR of 0.50 (95\% CI 0.12 to 1.98$).{ }^{16-18} 30$ Meta-analysis of five studies on asthma in women exposed to biomass fuel did not find a significant increase in the likelihood of developing asthma (OR 1.34, 95\% CI 0.93 to 1.93). Both meta-analyses used random-effect models due to significant heterogeneity among studies in children $\left(\mathrm{I}^{2}=88.6 \%, \mathrm{p}<0.001\right)$ and in women $\left(\mathrm{I}^{2}=58.6 \%, \mathrm{p}<0.046\right)$.

A funnel plot of all studies showed asymmetry (figure 3), with a significant Egger test $(p=0.014)$ and a non-significant Begg test $(p=0.925)$. Results from both tests were similar after exclusion of the highest OR from the study of Savitha et $a^{32}$ as an extreme outlier.

Possible confounding factors were explored using metaregression. The analysis addressed whether study design between case-control studies and cross-sectional studies, dichotomous smoking status and self-diagnosis or clinical diagnosis of respiratory illnesses contributed to the heterogeneity of the studies. Across all five groups study design did not contribute significantly to heterogeneity $(p>0.1)$. The type of diagnosis did not contribute significantly to heterogeneity either $(p>0.1)$. Of the three analyses on women, smoking status significantly contributed to the heterogeneity $(p=0.043)$ among studies on association between women's exposure to biomass fuel and risk of CB.

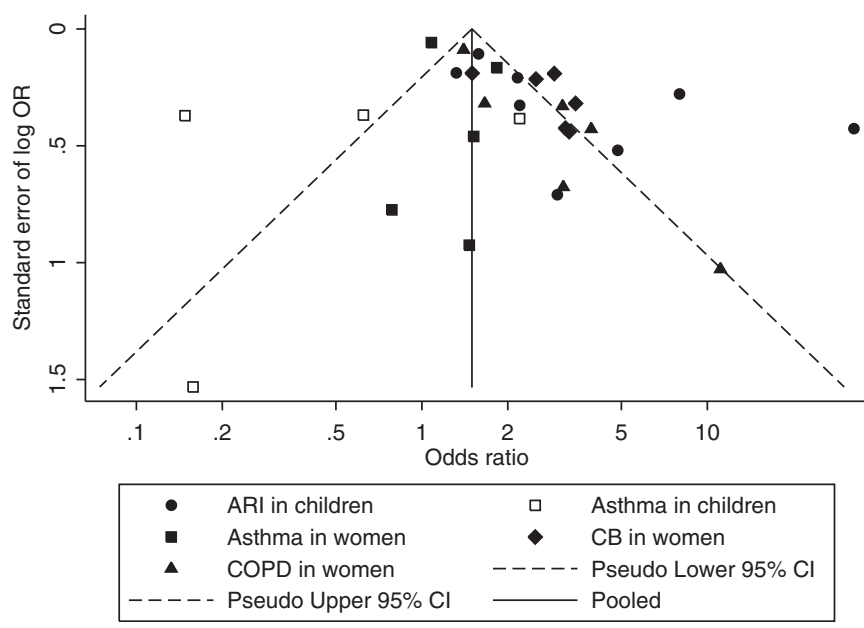

Figure 3 Funnel plot for all studies included in the meta-analysis. 
Smoking status did not contribute to the heterogeneity found among studies on children or women with asthma or COPD. Further analysis on effect modification showed that female smokers when exposed to biomass fuel smoke have a higher risk of CB (OR 2.89, 95\% CI 2.07 to 4.04) than female non-smokers (OR $1.50,95 \%$ CI 0.89 to 2.54 ).

\section{DISCUSSION \\ Main findings}

The systematic review yielded a set of 25 studies that clearly and adequately evaluated respiratory diagnoses as an outcome in rural women and children in the context of biomass fuel compared with other fuel exposure. The meta-analysis suggested that children were at least three times more likely to develop ARI when exposed to biomass fuel compared with alternative fuel types such as kerosene or LPG. Women were at least 2.4 times more at risk of developing COPD when exposed to biomass fuel smoke compared with other fuels. Women were 1.5 times more at risk of developing CB if they did not smoke and almost twice more at risk if they smoked.

Exposure of children to biomass fuel in rural domestic environments resulted in a pooled effect size from the present analysis that was relatively larger than the OR of 1.78 (95\% CI 1.45 to 2.18) between the association of solid fuel and pneumonia in children under $5 .{ }^{13}$ This might be due to a smaller sample of selected articles due to exclusion of coal as a non-biomass fuel and the general definition of the outcome in ARIs. Although there was evidence for heterogeneity among the selected articles, the large estimate suggested that there was a high risk for general ARI in children (with inherently underdeveloped immune systems) exposed to fuel smoke regardless of geographic location or type of biomass fuel. Reducing the exposure of children to biomass fuel smoke, by limiting their time in the kitchen or near open fires, would mean that children would be likely to have a much lower risk of ARIs. The cost-benefit of such exposure reduction should be assessed independently but is presumed to be highly beneficial.

Women, on the other hand, often take the responsibility of cooking for the family, such that it is more difficult to reduce their exposure to biomass smoke in the kitchen. The magnitude of association between exposure and CB and COPD in women was consistent with that found in other studies. ${ }^{14} 15$ This suggested that even though heterogeneity existed among studies, exposure to biomass fuel increases the risk of chronic respiratory diseases by approximately two and a half times. Based on this finding, using cleaner domestic fuel such as LPG or kerosene and providing better stove designs that allow smoke to be directed away through vents and chimneys may allow for the most reduction in chronic respiratory diseases.

Asthma in children and women had a non-significant association with exposure to biomass smoke, but only four appropriate studies on children and five studies on women were available for analysis. This reflects a paucity of original studies of how biomass smoke exposure affects the risk of asthma. The increased but non-significant risk of asthma in women when exposed to biomass smoke might, given a larger number of articles in the meta-analysis and greater power, become significant.

\section{Publication bias}

Although there were strong associations between biomass exposure and specific respiratory disease, we recognised that publication and reporting bias might affect the strength of the associations. Indeed, the Egger test and funnel plot asymmetry suggested publication bias exists in the sample of articles. This suggests that small studies with non-significant results may not have been published; if so, the pooled effect size may be overestimated. Alternatively, asymmetrical funnel plots may be caused by smaller but well-performed and focused studies within a meta-analysis legitimately demonstrating larger exposure effects. $^{26}$

\section{Heterogeneity among studies}

Heterogeneity among studies existed in numerous factors such as health outcome definition, stove type, length of exposure, household ventilation, country or climate, smoking status, diagnosis and study design. The differences in magnitude and consistency of association between exposure and ARIs in children might be due to the above factors in addition to age, immune system development, history of infections and access to health services. We explored the sources of heterogeneity with multivariate meta-regression to account for study design, mode of diagnosis and smoking status, for which we had adequate data. Neither study design nor mode of diagnosis contributed to the heterogeneity of the meta-analysis or significantly changed the pooled estimates. Studies with women who reported smoking showed that they have twice the risk of developing $\mathrm{CB}$ relative to women who reported being non-smokers. This smoking effect was not present in studies of asthma or COPD. In the five selected articles that focused on asthma in women, the women did not report smoking. Of the six articles that focused on COPD in women, two articles reported that $<25 \%$ of the women in the community smoked, which was consistent with previous studies on smoking prevalence-that is, that across different countries in several continents, in general, women in rural populations rarely smoke tobacco. ${ }^{21-23}$ Respiratory diseases in men were more likely to be attributed to smoking and occupational exposure. ${ }^{35}$ Secondhand smoke from male family members could also be a confounding factor even in the populations where women rarely smoke. The amount of exposure to secondhand smoke is difficult to quantify in such settings and is generally not quantified in the studies we evaluated; four studies included in the meta-analysis noted only that some family members smoke in the house. ${ }^{31363741}$ Given the lack of clarity in these data, we were unable to evaluate the potential influence of secondhand smoke effectively, though we considered it of minor influence relative to the massive particulate burden known to be generated by biomass fuel combustion.

There was heterogeneity of various biomass fuels and health outcome definition used in studies. Although wood, charcoal and animal dung are all biomass fuels, they have differential burning efficiency, albeit much lower than that of non-biomass fuels such as kerosene and LPG. Furthermore, duration of

Table 2 Risk associated with mixed fuel use, versus liquid petroleum gas use only, for a given respiratory outcome in women or children in rural settings

\begin{tabular}{|c|c|c|c|c|c|}
\hline $\begin{array}{l}\text { Author } \\
\text { Behera et } a l^{16}\end{array}$ & Location & Population & Age & Outcome & OR $(95 \%$ CI) \\
\hline \multirow[t]{5}{*}{ Behera et $a l^{16}$} & \multirow[t]{5}{*}{ India } & \multirow[t]{5}{*}{ Children } & \multirow[t]{5}{*}{$7-15$ years } & ARI & 4.95 (1.30 to 18.81$)$ \\
\hline & & & & $\begin{array}{l}\text { Asthmatic } \\
\text { bronchitis }\end{array}$ & $1.36(0.29$ to 6.43$)$ \\
\hline & & & & Bronchitis & 0.65 (0.10 to 4.09 ) \\
\hline & & & & Cough & 5.27 (1.08 to 25.78$)$ \\
\hline & & & & Wheeze & 2.02 (0.07 to 61.62$)$ \\
\hline Mishra et $a l^{42}$ & India & Women & $60+$ years & Asthma & 1.48 (1.12 to 1.97$)$ \\
\hline Mishra et $a l^{44}$ & India & Children & $0-3$ years & ARI & 1.41 (1.17 to 1.70$)$ \\
\hline
\end{tabular}

$A R I$, acute respiratory infection. 
exposure was variably measured in each study. Finally, as such studies generally lacked the technical equipment to measure the $\mathrm{PM}_{10}$ concentration, we were unable to analyse the data in terms of that specific metric. A study limitation is the diversity of exposures and multiple health outcomes and their definitions in the meta-analysis. We grouped common diagnoses of similar health outcomes, although we recognise that the outcome terms are variably defined. We recognise that there are a lack of studies with randomised controlled trials and exposure assessments, which could better quantify the impact of biomass fuel smoke on respiratory health and better address unaccounted confounding. Planning of locally appropriate interventions in each setting would be complicated by the limitation in local environment, resources and local support.

\section{Mixed fuel}

We noted interesting observations regarding 'mixed fuel' or 'multiple fuel' use. Mixed fuel use is the use of non-biomass fuels and biomass fuels in the household, which reflects more closely those households that are progressing from biomass fuel use to kerosene and LPG and conditions where resource scarcity and uncertainty predominate. ${ }^{3}$ Many of these alternative fuels are affordable only through government subsidies and are allotted periodically. As the end of the period approaches and alternative fuels are running out, households may partly revert back to biomass fuel use. In the literature, three studies ${ }^{1642} 44$ compared exposure to mixed fuel and alternative fuels in outcomes on ALRI, asthma, bronchitis and respiratory symptoms (cough and wheeze), as summarised in table 2. These studies suggested increased risk in several of the end points, in association with mixed fuel use more than sole use of biomass fuel, but beg further data.

\section{CONCLUSION}

The detrimental effect of biomass fuel smoke exposure on respiratory health is recognised in the existing body of literature. This meta-analysis adds to that knowledge by quantifying the association between biomass fuel use and specific respiratory end points, in a specific context of women and children in a rural setting. Our results suggest that household biomass fuel use confers significant risk for ARI in children, and CB and COPD in women, while there remains a gap of knowledge in the association between asthma and biomass fuel exposure. A focus on community education on the harmful effect of biomass fuel exposure may mobilise demand for improved stove installations and better household ventilation; these findings may also motivate longer term development including rural electrification and strategies for poverty reduction.

Acknowledgements We thank Mimi Rogers-Doyle for helpful guidance regarding study methodology.

Funding Department of Medicine, University of British Columbia.

Competing interests None.

Provenance and peer review Not commissioned; externally peer reviewed.

\section{REFERENCES}

1. Fullerton DG, Bruce N, Gordon SB. Indoor air pollution from biomass fuel smoke is a major health concern in the developing world. Trans $R$ Soc Trop Med Hyg 2008;102:843-51.

2. Smith KR, Mehta S, Maeusezahl-Feuz M. Indoor air-pollution from solid fuel use. In: Ezzati MLA, Rodgers A, Murray CJL, eds.Comparative Quantification of Health Risks: Global and Regional Burden of Disease Due to Selected Major Risk Factors. Global and Regional Burden of Disease Attributable to Selected Major Risk Factors. Geneva: World Health Organization, 2004:1435-93.
3. Masera 0, Saatkamp BD, Kammen D. From linear fuel switching to multiple cooking strategies: A critique and alternative to the energy ladder model World Development. 2000;28:2083-103.

4. Torres-Duque C, Maldonado D, Perez-Padilla R, et al. Biomass fuels and respiratory diseases: a review of the evidence. Proc Am Thorac Soc 2008;5:577-90.

5. Bruce N, Perez-Padilla R, Albalak R. Indoor air pollution in developing countries: a major environmental and public health challenge. Bull World Health Organ 2000;78:1078-92.

6. Ezzati M, Kammen D. Indoor air pollution from biomass combustion and acute respiratory infections in Kenya: an exposure-response study. Lancet 2001;358:619-24.

7. Regalado J, Perez-Padilla R, Sansores R, et al. The effect of biomass burning on respiratory symptoms and lung function in rural Mexican women. Am J Respir Crit Care Med 2006:174:901-5.

8. O'Brien KL, Wolfson LJ, Watt JP, et al. Burden of disease caused by Streptococcus pneumoniae in children younger than 5 years: global estimates. Lancet 2009;374:893-902.

9. Mathers CD, Lopez AD, Murray CJL. The burden of disease and mortality by condition: data, methods, and results for 2001. In: Lopez AD, Mathers CD, Ezzati M, et al, eds. Global Burden of Disease and Risk Factors. New York: Oxford University Press, 2006:45-93

10. Campbell H. Indoor air pollution and acute lower respiratory infections in young Gambian children. Health Bull (Edinb) 1997:55:20-31.

11. Noonan CW, Balmes JR. Biomass smoke exposures: health outcomes measures and study design. Inhal Toxicol 2010;22:108-12.

12. Smith KR, Samet JM, Romieu I, et al. Indoor air pollution in developing countries and acute lower respiratory infections in children. Thorax 2000;55:518-32.

13. Dherani M, Pope D, Mascarenhas $M$, et al. Indoor air pollution from unprocessed solid fuel use and pneumonia risk in children aged under five years: a systematic review and meta-analysis. Bull World Health Organ 2008;86:390-8C

14. Hu G, Zhou Y, Tian J, et al. Risk of COPD from exposure to biomass smoke: a metaanalysis. Chest 2010;138:20-31.

15. Kurmi OP, Semple S, Simkhada P, et al. COPD and chronic bronchitis risk of indoor air pollution from solid fuel: a systematic review and meta-analysis. Thorax 2010;65:221-8.

16. Behera D, Sood P, Singh S. Passive smoking, domestic fuels and lung function in north Indian children. Indian J Chest Dis Allied Sci 1998:40:89-98.

17. Fagbule D, Ekanem EE. Some environmental risk factors for childhood asthma: a case-control study. Ann Trop Paediatr 1994;14:15-19.

18. Noorhassim I, Rampal KG, Hashim JH. The relationship between prevalence of asthma and environmental factors in rural households. Med $\mathrm{J}$ Malaysia 1995:50:263-7.

19. Qureshi KA. Domestic smoke pollution and prevalence of chronic bronchitis/asthma in a rural area of Kashmir. Indian J Chest Dis Allied Sci 1994;36:61-72.

20. Smith-Sivertsen T, Diaz E, Pope D, et al. Effect of reducing indoor air pollution on women's respiratory symptoms and lung function: the RESPIRE Randomized Trial, Guatemala. Am J Epidemiol 2009;170:211-20.

21. Ashraf A, Quaiyum MA, $\mathrm{Ng} \mathrm{N}$, et al. Self-reported use of tobacco products in nine rural INDEPTH Health and Demographic Surveillance Systems in Asia. Glob Health Action 2009:2 doi:10.3402/gha.v2i0.1999.

22. Kitange HM, Swai $A B$, Masuki $G$, et al. Coronary heart disease risk factors in sub-Saharan Africa: studies in Tanzanian adolescents. J Epidemiol Community Health 1993;47:303-7.

23. Liu B0, Peto R, Chen ZM, et al. Emerging tobacco hazards in China: 1. Retrospective proportional mortality study of one million deaths. BMJ 1998;317:1411-22

24. Song F, Sheldon TA, Sutton AJ, et al. Methods for exploring heterogeneity in meta-analysis. Eval Health Prof 2001;24:126-51.

25. Egger M, Davey Smith G, Schneider M, et al. Bias in meta-analysis detected by a simple, graphical test. BMJ 1997;315:629-34

26. Sterne JA, Egger M, Smith GD. Systematic reviews in health care: investigating and dealing with publication and other biases in meta-analysis. BMJ 2001:323:101-5.

27. Akhtar T, Ullah Z, Khan MH, et al. Chronic bronchitis in women using solid biomass fuel in rural Peshawar, Pakistan. Chest 2007;132:1472-5.

28. Collings DA, Sithole SD, Martin KS. Indoor woodsmoke pollution causing lower respiratory disease in children. Trop Doct 1990;20:151-5.

29. Dennis RJ, Maldonado D, Norman S, et al. Woodsmoke exposure and risk for obstructive airways disease among women. Chest 1996;109:115-19.

30. Melsom T, Brinch L, Hessen J0, et al. Asthma and indoor environment in Nepal. Thorax 2001:56:477-81.

31. Morris K, Morgenlander M, Coulehan JL, et al. Wood-burning stoves and lower respiratory tract infection in American Indian children. Am J Dis Child 1990:144:105-8.

32. Savitha MR, Nandeeshwara SB, Pradeep Kumar MJ, et al. Modifiable risk factors for acute lower respiratory tract infections. Indian J Pediatr 2007;74:477-82

33. Sezer H, Akkurt I, Guler N, et al. A case-control study on the effect of exposure to different substances on the development of COPD. Ann Epidemiol 2006;16:59-62.

34. Behera D, Chakrabarti T, Khanduja KL. Effect of exposure to domestic cooking fuels on bronchial asthma. Indian J Chest Dis Allied Sci 2001:43:27-31.

35. Ehrlich RI, White N, Norman R, et al. Predictors of chronic bronchitis in South African adults. Int J Tuberc Lung Dis 2004:8:369-76.

36. Ekici A, Ekici M, Kurtipek E, et al. Obstructive airway diseases in women exposed to biomass smoke. Environ Res 2005;99:93-8. 
37. Golshan M, Faghihi M, Marandi MM. Indoor women jobs and pulmonary risks in rural areas of Isfahan, Iran. Respir Med 2002;96:382-8.

38. Kilabuko JH, Matsuki H, Nakai S. Air quality and acute respiratory illness in biomass fuel using homes in Bagamoyo, Tanzania. Int J Environ Res Public Health 2007:4:39-44.

39. Kiraz K, Kart L, Demir R, et al. Chronic pulmonary disease in rural women exposed to biomass fumes. Clin Invest Med 2003;26:243-8.

40. Liu S, Zhou $Y$, Wang $X$, et al. Biomass fuels are the probable risk factor for chronic obstructive pulmonary disease in rural South China. Thorax 2007:62:889-97.

41. Malik SK. Exposure to domestic cooking fuels and chronic bronchitis. Indian J Chest Dis Allied Sci 1985;27:171-4.

42. Mishra V. Effect of indoor air pollution from biomass combustion on prevalence of asthma in the elderly. Environ Health Perspect 2003;111:71-8.
43. Mishra V. Indoor air pollution from biomass combustion and acute respiratory illness in preschool age children in Zimbabwe. Int J Epidemiol 2003;32:847-53.

44. Mishra V, Smith KR, Retherford RD. Effects of cooking smoke and environmental tobacco smoke on acute respiratory infections in young Indian children. Popul Environ 2005;26:375-96

45. Mishra V, Retherford RD. Cooking smoke increases the risk of acute respiratory infection in children. Natl Fam Health Surv Bull 1997:8:1-4.

46. Shrestha IL, Shrestha SL. Indoor air pollution from biomass fuels and respiratory health of the exposed population in Nepalese households. Int J Occup Environ Health 2005;11:150-60

47. Uzun K, Ozbay B, Ceylan E, et al. Prevalence of chronic bronchitis-asthma symptoms in biomass fuel exposed females. Environ Health Prev Med 2003;8:13-17.

\section{Lung alert}

\section{Sildenafil does not improve 6 min walk distance in advanced idiopathic pulmonary fibrosis}

It has been postulated that sildenafil, a phosphodiesterase- 5 inhibitor and pulmonary artery vasodilator, may improve gas exchange in advanced idiopathic pulmonary fibrosis by preferentially increasing perfusion to well-ventilated areas of lung. This double-blind randomised placebo controlled study was designed to investigate the effect of sildenafil on 6 min walk distance $(6 \mathrm{MWD})$ in patients with advanced idiopathic pulmonary fibrosis (carbon monoxide diffusing capacity $<35 \%$ predicted value).

A total of 180 patients from 14 centres were randomised to sildenafil or placebo with reassessment of $6 \mathrm{MWD}$ at 12 weeks. Both groups received open-label sildenafil from weeks 12 to 24 . There was no significant difference in the primary outcome measure between the two groups (the proportion of patients with improved $6 \mathrm{MWD}$ of $\geq 20 \%$ ). Small significant improvements were seen in secondary outcome measures at 12 weeks in the sildenafil treatment group including carbon monoxide diffusing capacity, oxygen partial pressure, St George's respiratory questionnaire total score and SF-36 general health score. These improvements were not observed in the placebo group who subsequently received sildenafil.

The study failed to meet the primary outcome measure, however the authors suggest that improvements in secondary outcomes were of clinical significance. They accept that assessment of the relation between treatment effect and severity of pulmonary vascular disease would have been valuable. The authors conclude that the therapeutic efficacy of sildenafil in advanced idiopathic pulmonary fibrosis remains uncertain and that further trials are necessary.

- Zisman D, Schwarz M, Anstrom K, et al; the Idiopathic Pulmonary Fibrosis Clinical Research Network. A controlled trial of sildenafil in advanced idiopathic pulmonary fibrosis. N Engl J Med 2010;363:620-8.

\section{Lavender}

Correspondence to M Lavender, Specialist Registrar, Salisbury District Hospital, Salisbury SP2 8BJ, UK; melanie.lavender@salisbury.nhs.uk

Provenance and peer review Not commissioned; not externally peer reviewed.

Published Online First 11 October 2010

Thorax 2011;66:239. doi:10.1136/thx.2010.145664 